\title{
François Dorval-Langlois sieur de Fancan, Le Tombeau des Romans
}

\section{Daniela Dalla Valle}

\section{(2) OpenEdition}

1 Journals

\section{Edizione digitale}

URL: http://journals.openedition.org/studifrancesi/36011

DOI: 10.4000/studifrancesi.36011

ISSN: 2421-5856

\section{Editore}

Rosenberg \& Sellier

\section{Edizione cartacea}

Data di pubblicazione: 1 juillet 2005

Paginazione: 154

ISSN: 0039-2944

\section{Notizia bibliografica digitale}

Daniela Dalla Valle, «François Dorval-Langlois sieur de Fancan, Le Tombeau des Romans», Studi

Francesi [Online], 145 (XLIX | I) | 2005, online dal 30 novembre 2015, consultato il 20 avril 2021. URL: http://journals.openedition.org/studifrancesi/36011; DOI: https://doi.org/10.4000/studifrancesi. 36011

Questo documento è stato generato automaticamente il 20 avril 2021.

\section{(c)}

Studi Francesi è distribuita con Licenza Creative Commons Attribuzione - Non commerciale - Non opere derivate 4.0 Internazionale. 


\title{
François Dorval-Langlois sieur de Fancan, Le Tombeau des Romans
}

\author{
Daniela Dalla Valle
}

NOTIZIA

FRANÇOIS DORVAL-LANGLOIS SIEUR DE FANCAN, Le Tombeau des Romans, texte établi d'après

l'édition de Claude Morlot, Paris, 1626, a cura di F. GREINER, Reims, Publication du Centre de Recherche sur la Transmission des Modèles Littéraires et Esthétiques, 2003, pp. 114.

1 Il volume riproduce e annota uno dei primissimi testi critici scritti sul romanzo, accanto a quelli di Sorel, di Chapelain, di Huet, di Du Plaisir. Suddiviso in due parti, una Contre les romans e una Pour les romans, il Tombeau fornisce un'importantissima testimonianza critica sul genere nuovo che, appunto nel 1626, incominciava ad affermarsi. Chi si occupa del romanzo secentesco non potrà che approvare l'iniziativa di ripubblicare questo breve testo, annotandolo, corredandolo di un indice dei nomi e, soprattutto, di una prefazione accurata, che indaga sull'autore, analizza l'opera, ne cerca le fonti, ne fissa gli argomenti, la lingua, lo stile e la successiva fortuna. 